\title{
Acionamentos geopolíticos num show de música pop em Cuba
}

Thiago Soares

Resumo: Diante de um contexto histórico de tensionamento político e econômico entre Cuba e Estados Unidos, toma-se um espetáculo de música pop ocorrido em março de 2016 na Tribuna Anti-imperialista em Havana e protagonizado pelo grupo de música eletrônica Major Lazer como uma performance em torno da memória cultural nas Américas, conforme postula Diana Taylor (2013). A encenação de disposições performáticas dos músicos e do público remete a rituais que evidenciam contradições em torno da presença de vestígios de produtos da cultura norte-americana em território cubano. Debate-se as rasuras das políticas comunicacionais restritivas do governo cubano e a ostentação de ícones ligados aos Estados Unidos por parte da juventude de Cuba como questionamentos em torno de um projeto de nação.

Palavras-chaves: performance; música pop; gêneros musicais; geopolítica; Cuba.

Abstract: Geopolitical assemblages in a pop music concert in Cuba - Facing a historical context of political and economic tension between Cuba and the United States, we investigate a pop music concert held in March 2016 in Anti-Imperialist Tribune, Havana, played by electronic music group Major Lazer, as a performance around the cultural memory in America, as postulated by Diana Taylor (2013). The staging of performance arrangements of musicians and the audience refers to rituals that reveal contradictions around the presence of American products traces in Cuban territory. We debate the erasures of restrictive communication policies by the Cuban government and the display of icons linked to United States by the Cuban youth as an inner question about a national project built in the Caribbean island.

Keywords: performance; pop music; music genres; geopolitics; Cuba.

Dia 6 de março de 2016. Leandro Sanchez, 24 anos, usa sabão com parafina para ajustar seu penteado punk, para colocar os cabelos arriba. Trata-se de uma engenharia que dura cerca de meia hora, entre tomar banho, elaborar a solução que une sabão e parafina, aplicá-la nos cabelos e penteá-los. Apesar de se intitular punk e de ser um dos músicos da banda punk cubana Stafilococos, Leandro está se preparando para ir 
ao show do grupo de música eletrônica dançante Major Lazer ${ }^{1}$, que tem entre os integrantes o produtor musical Diplo - o primeiro concerto em Havana de um artista pop norte-americano desde o restabelecimento das relações diplomáticas entre Cuba e Estados Unidos, em dezembro de 2014. Embora não goste de música eletrônica "pop, como esta" (o Major Lazer, frequentemente, não faz músicas apenas com batidas eletrônicas sem vocais. Seus integrantes convidam artistas que colocam vozes em suas canções), Leandro não se refuta a ir a um espetáculo musical de um artista de que não gosta. "Temos tão poucos shows aqui em Cuba que, quando aparece um, todo mundo vai", atesta.

O show do Major Lazer ocorreu na Tribuna Anti-imperialista José Martí, uma área aberta, no final do Malecón (a mureta que circunda a parte litorânea da cidade), formada por um palco construído no ano 2000 como um monumento às vítimas das injustiças causadas pelos norte-americanos. A Tribuna Anti-imperialista também era o local em que os líderes comunistas faziam discursos contra os Estados Unidos, reforçando os ideais do socialismo e da permanência de Cuba como nação independente no contexto caribenho. Por trás do palco da tribuna, há mastros de bandeiras que eram usados para bloquear a visão do prédio governamental americano. As bandeiras foram retiradas em 2009, liberando a vista do edifício, que passou a sediar, em 2015, a embaixada dos Estados Unidos na ilha.

Enquanto Leandro desce pela Calle 23, inúmeros grupos de jovens cubanos também seguem na mesma direção, empunhando garrafas de rum, litrões de refrigerante e cervejas. Percebo que há muitos cubanos vestidos com acessórios com que evocam a cultura americana. Há bonés de times de basquete da NBA (a liga mais importante dos Estados Unidos), camisas com as cores e os símbolos da bandeira dos EUA, $t$-shirts de bandas de rock. Começo a delinear, através da moda, uma problemática que, talvez, permeie toda esta pesquisa ${ }^{2}$ : de que maneira parte da juventude cubana que não se identifica com o projeto de nação evocado pelo socialismo lida com a cultura pop, marcadamente anglófila e centrada, em grande parte, em valores norte-americanos?

\section{Contradições na estátua de José Martí}

Esta aparente contradição - ir a um local chamado Tribuna Anti-imperialista para assistir a um espetáculo de um grupo de música eletrônica dos Estados Unidos -

1 Major Lazer é um projeto de eletronic dance music (EDM), ou música eletrônica dançante, forma genérica com que a crítica musical se refere a DJs e produtores que ascenderam à condição de estrelas da música após a década de 1990. O maior expoente do grupo é o DJ e produtor norte-americano Diplo. Integram também o DJ jamaicano Walshy Fire e Jillionaire (de Trinidad e Tobago). Usamos o Major Lazer como "grupo norte-americano" em função do protagonismo de Diplo e pelo sistema produtivo de gravação que está localizado na Califórnia, na costa oeste dos Estados Unidos.

2 Este artigo faz parte da pesquisa "Música pop em Cuba: enfrentamentos políticos e midiáticos", com recursos obtidos por meio do edital CNPq/MCTI 25/2015 - Ciências Humanas, Sociais e Sociais Aplicadas. A primeira ida a campo se deu no mês de março de 2016, usando uma metodologia de inspiração etnográfica que visa ao contato com sujeitos que integram aquele contexto. Numa ida de férias a Cuba, em 2015, tive contato com fãs de música pop (das cantoras Madonna e Lady Gaga) em Havana. Esses mediadores foram importantes para que eu pudesse me inserir entre os apreciadores de música pop anglófila em Cuba e conhecer Leandro Sanchez, que acompanhei nesta ida ao show do Major Lazer. 
acentua-se diante da ocupação e da sociabilidade resultantes de jovens cubanos naquele espaço. Um dos marcos da Tribuna Anti-imperialista é uma estátua do líder cubano José Martí, que carrega uma criança nos braços e aponta para o edifício da embaixada dos Estados Unidos. Abaixo da estátua, cravado em letras douradas, lê-se o texto atribuído a Simon Bolívar: "os Estados Unidos, que parecem destinados pela providência a propagar miséria à América em nome da liberdade". Eu me aproximo da estátua para ler a inscrição e vejo um jovem cubano negro, de boné preto (Fig.1), manuseando um celular amarelo, com a camisa de design geométrico, na qual está escrito: "New York". Outro garoto, ao lado, também "aos pés" da estátua do líder José Martí, está com um boné xadrez com o símbolo NY, da cidade de Nova York. A recusa histórica do líder Simon Bolívar parece problematizada diante dos jovens que estão ali, naquele espaço, prestes a assistir a um concerto de música eletrônica.

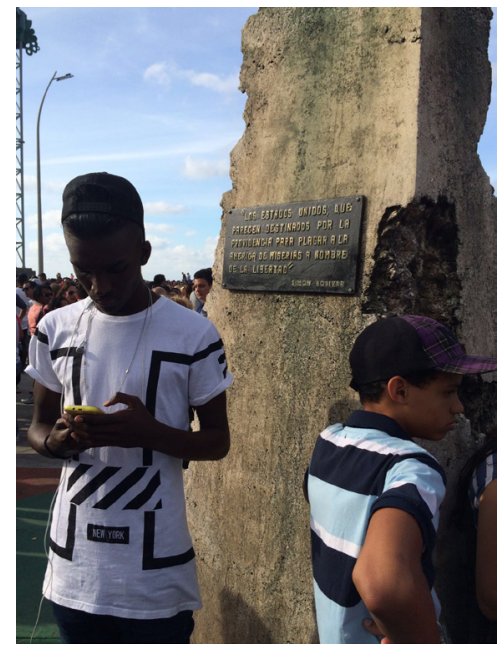

Fig.1. Jovem maneja celular sob estátua com dizeres antiamericanos

A ressignificação dessa estátua de José Martí, especificamente, não é algo novo, sobretudo em função de sua estratégica posição diante do edifício oficial mais importante dos Estados Unidos em Cuba - sua embaixada, local a que centenas de cubanos vão, diariamente, enfrentar filas na Calle Calzadas (que dá acesso ao prédio) para tentar visto e negociar aspectos migratórios com o país vizinho. Cidadãos cubanos que se opõem às aproximações diplomáticas entre Cuba e Estados Unidos chamam essa área de "El Tontódromo", algo que pode ser traduzido como Bestódromo, um local para pessoas bobas que tentam, em vão, "los papeles" (os papéis) para ir, por exemplo, a Miami. Curiosa é a narrativa do jornalista cubano Fernando Dámaso (2014), no blog Diario de Cuba, que ecoa relatos populares sobre a estátua de José Martí, segurando uma criança e apontando 
para a embaixada dos EUA: "alguns desrespeitosos asseguram que Martí está dizendo à criança: 'ali é onde se dão os vistos'" (Fig. 2). Sobre as hastes de bandeiras existentes ao redor do prédio da embaixada, Dámaso também faz um relato irônico. Segundo ele, o árido entorno do prédio, com as hastes que, outrora, eram quase sempre ocupadas por bandeiras pretas para "ocultar" a vista dos vidros da embaixada, parecia evocar uma espécie de ideia de que "se tratava de um ambiente para convenções dos piratas do Caribe, rodeado de seguranças também vestidos de preto $^{\prime 3}$.

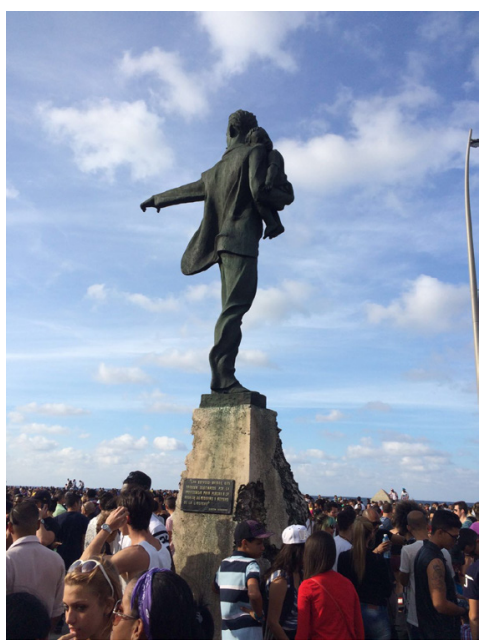

Fig. 2. Jovens ao redor da estátua de José Martí no Malecón

Apesar das aparentes contradições em torno do espetáculo do Major Lazer na Tribuna Anti-imperialista, esta não foi efetivamente a primeira ocorrência de um evento desta natureza. Em 2005, o grupo norte-americano Audioslave também realizou um concerto no local e registrou o espetáculo num DVD. Essa iconografia contraditória parece ser atenuada se levarmos em consideração justificativas econômicas para a realização de concertos de grande porte em Havana. Em função da própria natureza dos espetáculos que ocorrem no país, que são gratuitos, sobretudo em decorrência dos baixos salários dos cubanos (que recebiam, em 2015, o equivalente a 30 CUCs por mês, algo como US\$ 30), a Tribuna Anti-imperialista, que já detém uma estrutura de palco e arcos de ferro e alumínio, acaba sendo uma opção que barateia as operações de montagem de estruturas para shows. O espetáculo do Major Lazer em Havana foi realizado pela Fundação Musicabana, por meio do produtor Fabien Pisani, filho do famoso músico cubano Pablo Milanés, que justifica o uso da Tribuna Anti-imperialista como recurso de barateamento da produção do espetáculo - e não como uma espécie de "afronta" a toda a história de

3 Para o relato completo: http://www.diariodecuba.com/cuba/1406364657_9679.html. Acesso em 13 de março de 2016. 
resistência antiamericana ali presente. "É também perto do mar e aberto, de fácil acesso. Talvez, fazer show ali signifique um momento de transição nas relações entre Cuba e Estados Unidos", afirma Pisani ${ }^{4}$.

Embora tenha a chancela de produzir espetáculos musicais na ilha, qualquer show realizado em Cuba passa por uma ampla negociação com o Estado. Joe Coscarelli (2016) assegura que, em geral, há indicações para "despolitizar" os concertos, entendendo esta "despolitização" como a não menção nem ao regime cubano, nem à realização de comentários ao passado ou ao futuro da ilha. O processo de negociação deve passar pelo Instituto Cubano de La Musica (ICM), órgão estatal que aprova a realização dos atos.

A perspectiva de realização do show também era a de romper com certos estereótipos nostálgicos em relação aos produtos culturais cubanos. "Eu não estava interessado em realizar um ato nostálgico que lembrasse a Cuba dos anos 1950. Meu interesse era projetar a Havana de 2050", diz Fabien Pisani à reportagem do The New York Times ${ }^{5}$. Segundo dados contidos na reportagem, o concerto do Major Lazer teria custado US\$ 150 mil, em transporte de equipamentos e viagens para 24 pessoas que integram a equipe. A verba teria sido integralmente custeada pelo grupo, com auxílio do fundo cultural da embaixada dos Estados Unidos. Ao Instituto Cubano de La Musica, coube arcar com a liberação do local, seguros médicos, bombeiros e segurança. Embora não oficialmente relacionado, o show do Major Lazer acabou sendo uma espécie de abertura do mês de visita do presidente Barack Obama a Cuba, em março de 2016. Trata-se da primeira visita de um chefe de Estado dos EUA à ilha após 88 anos.

Pergunto para Leandro Sanchez como o grupo Major Lazer se tornou popular em Cuba, já que a música norte-americana, embora toque nas rádios e goze de alguma popularidade, não chega a competir, por exemplo, com o mais popular gênero musical da ilha, o reggeatón. "Algumas músicas de Major Lazer, como Lean On, foram distribuídas nos paquetes digitales com seriados americanos, filmes estrangeiros e música pop", diz. Paquetes digitales podem ser traduzidos como pacotes digitais e são conjuntos de arquivos separados por gêneros ou temas, baixados semanalmente em oficinas digitales (o equivalente no Brasil às lan houses), comercializados a 1 CUC (quase US\$ 1) por conteúdo disponibilizado e adquiridos por usuários por meio de pen drives ou disco duros, os HDs externos. Ou seja, embora pouco exibido em canais oficiais de comunicação massiva, a televisão e a rádio estatais, o Major Lazer chegou aos ouvidos dos jovens de Cuba por meio de práticas da cultura digital.

Os conteúdos dos paquetes digitais variam e, portanto, a figura de mediadores culturais se faz importante para garantir a qualidade dos produtos que são copiados. Neste caso em especial, no tocante à música, um dos mais importantes paqueteros de Havana

4 O texto completo está disponível em: http://pitchfork.com/thepitch/1047-what-cuba-thought-of-major-lazershistoric-havana-show/. Acesso em 13 Mar. 2016.

5 O texto completo está disponível em: http://www.nytimes.com/2016/03/08/arts/music/diplo-and-major-lazerbring-their-brand-of-music-to-cuba.html?_r=1. Acesso em 13 Mar. 2016. 
é o DJ Alexandre, que possui produtora de videoclipes e agencia shows de artistas de reggeatón na ilha, e cuja inclusão de alguma canção num de seus paquetes semanais pode ser garantia de ampla circulação, sobretudo entre os reggeatoneros, que funcionam como importantes recomendadores de música entre os jovens de Havana.

\section{Sobre performance e roteiro}

"Diplo está usando uma camisa da equipe cubana de beisebol e acenando com uma bandeira de Cuba", relata o texto de Spercer Parts, do site de música Pitchfork. A cena do Major Lazer e seu DJ mais importante, Diplo, tocando na Tribuna Anti-imperialista, em Havana, parece ser uma forma de pensar, de maneira mais ampla, a performance como objeto/processo das "muitas práticas e eventos - dança, teatro, ritual, comícios políticos, funerais - que envolvem comportamentos ensaiados, teatrais ou convencionais/apropriados para a ocasião", como atesta Diana Taylor (2013). Para a autora, a performance constitui a lente metodológica que permite que pesquisadores avaliem eventos como metáforas.

Obediência cívica, resistência, cidadania, gênero, etnicidade e identidade sexual, por exemplo, são ensaiados e performatizados diariamente na esfera pública.

Entender esses itens como performances sugere que a performance também funciona como uma epistemologia. (ibidem, p. 27)

O que Diana Taylor (ibidem) parece querer indicar é o reconhecimento da performance como um modo de conhecer, através das encenações, as culturas, suas corporalidades e teatralidades. A organização da "totalidade analisável" sugere o reconhecimento de que a performance e a estética da vida cotidiana "refletem a especificidade cultural e histórica existente tanto na encenação quanto na recepção" (ibidem, p. 27). Ou seja, em certo sentido, performances estão sempre in situ: são inteligíveis nas estruturas dos ambientes imediatos e das questões que ali se inscrevem. Compreende-se que shows de música pop operam sob a dicotomia da performance. Os corpos ali apresentados trazem consigo a ideia de movimentos expressivos como reservas mnemônicas, "incluindo movimentos padronizados, feitos e lembrados por corpos; movimentos residuais, guardados implicitamente em imagens ou palavras; e movimentos imaginários, sonhados em mentes, como partes constitutivas delas" (ROACH, 1996, p. 26).

Quando pensamos que o concerto do Major Lazer foi uma ação promovida também pelo estado cubano, é possível reconhecer uma dimensão performativa nestas disputas: o governo que realiza um ato para os jovens (tentando negociar com gerações distantes dos ideais da Revolução); o Major Lazer, que quer "fazer história" sendo o primeiro grupo norte-americano de eletronic dance music (EDM) a fazer um espetáculo daquela dimensão na ilha. Percebe-se, portanto, que Cuba é um país que, em função de sua história e condição geopolítica, aciona, na música pop, um imaginário sobre um lugar de marcação 
de uma diferença. Artistas pop que para lá se dirigem parecem querer indicar algo de ordem performativa ${ }^{6}$ : adesão a dinâmicas socialistas, críticas ao embargo econômico, reconhecimento da luta de um povo, comoção em torno da resistência.

Os atos, isolados ou conectados entre si, suas encenações e tomadas de posição ecoam a perspectiva de que "as performances não podem nos dar acesso à outra cultura, permitindo vê-la em profundidade, mas elas certamente nos dizem muito sobre nosso desejo desse acesso e refletem a política de nossas interpretações" (TAYLOR, 2013, p. 32). Debate-se, portanto, a dramaturgia dos eventos, seus componentes estéticos e lúdicos, agenciamentos culturais. Se tomarmos o show do Major Lazer como uma teatralidade, entendemos também que tal encenação comporta um roteiro, uma "configuração paradigmática que conta com participantes supostamente ao vivo, estruturados ao redor de um enredo esquemático, com um fim pretendido (apesar de adaptável)" (ibidem, p. 41).

Estrutura-se um modo de observar o espetáculo como um roteiro de um encontro, uma narrativa que se apresenta encenada: o claro destacamento em torno de um dos artistas do grupo, o DJ Diplo, de origem norte-americana, e sua exibição diante da embaixada dos Estados Unidos para a plateia de habitantes de Cuba. Duas nações, formatadas a partir de tensões diplomáticas que se estendem já por mais de 50 anos, frente a frente, num ambiente lúdico. Qual o roteiro que se desenrola naquele acontecimento? Diana Taylor (ibidem) propõe uma espécie de método de análise dos roteiros como uma forma de entender as performances não a partir de textos e narrativas, mas daquilo que é uma espécie de sumário, esboço, rascunho que dá informação sobre as cenas, situações. O encontro entre duas nações se dá a partir dos corpos dos seus cidadãos, dos viventes. Há planejamentos anteriores, formas de aproximação, de negociação. Pensar por meio da ideia de roteiro nos fornece subsídios para reconhecer os clichês das encenações: os fantasmas, as imagens, os estereótipos.

O grande roteiro na história das Américas, nos lembra Taylor (ibidem), é o do descobrimento: personagens se delineiam nestas narrativas históricas (o descobridor, o conquistador, os nativos, entre outros). Tais narrativas históricas assombram o presente quando reencenadas, apresentadas como inéditas, podendo "assustar" nossa compreensão diante de outro final possível. Metodologicamente, os roteiros nos impelem a observar mais atentamente os gestos, as atitudes, os tons - simultaneamente, montagem e ação, ativação e moldura de dramas. A montagem exibe elementos como encontro, conflito, resolução, desenlace. Sobre o método do roteiro como análise de performances, Taylor (ibidem) sugere a observação analítica de, ao menos, três grandes quadros constituintes da dramaticidade:

6 Entende-se o performativo a partir dos estudos de filosofia e retórica, notadamente de J.L. Austin, Jacques Derrida e Judith Butler. O performativo, para Austin (1975, p. 6), refere-se a casos em que a "emissão de um enunciado (utterance) é também a realização de uma ação". O peso legal do "sim" numa cerimônia de casamento seria um exemplo de agenciamento do performativo. 
- O local físico onde se dá a apresentação, uma cena que denota intencionalidade em termos artísticos e políticos, o que sinaliza estratégias conscientes de exibição. "Lugares nos permitem pensar sobre possibilidades e limites de ação. Porém, a ação também define o lugar" (ibidem, p. 62).

- A corporalidade dos atores sociais ou a construção social dos corpos em contextos definidos, os detalhes visuais, as peculiaridades da aparência, dos gestos e das falas; as zonas tensivas entre enredo e personagem e o que se apresenta como solução expressiva.

- A montagem das ações como estruturas que seguem fórmulas, predispõem resultados e, também, abrem margem para se pensar inversões, paródias, mudanças. "O roteiro força-nos a nos situar em relação a ele; como participantes, testemunhas ou espectadores" (ibidem, p. 62). A montagem das ações comumente invoca situações passadas, que fazem parte de um acervo de memória e de sua potência significante.

A partir dessas premissas metodológicas, delineamos dois quadros performáticos que funcionam como formas de entendimento das relações entre duas nações formadas a partir de um espetáculo de música pop. Sobre o show do Major Lazer em Havana, no mês da visita do presidente Barack Obama a Cuba em março de 2016, repousam encenações que recaem sobre: a) a mitologia e o zelo em torno de uma amizade abalada; b) a demarcação de performatividades em torno de conquistas territoriais.

\section{Tensões de um encontro: o estrangeiro e o jinetero}

Em seu ensaio Políticas da Amizade, Jacques Derrida (1997) sustenta a hipótese de que a amizade é uma efemeridade, ao mesmo tempo afirmada e colocada em dúvida. A política da amizade estaria naquilo que podemos supor ser o "teste" sobre o estatuto do amigo, a eterna desconfiança que se tem em torno do vestígio dos atos aproximativos. Amizade seria, então, de uma ordem dinâmica. Não uma propriedade ou qualidade do sujeito, mas algo que traria à tona também seu caráter utilitário - possíveis jogos de interesse sob cálidas máscaras de afeto. Para Derrida (ibidem), a amizade é a eterna luta contra o esquecimento - ou a incessante memória do vivido. Afinal de contas, como nos lembra Aristóteles: o amigo é o outro em si mesmo. "Uma alteridade imanente na 'mesmidade'. Tornar-se outro no mesmo", como afirma Agamben (2013, p. 83).

\footnotetext{
Vestindo uma camisa cubana, Walshy Fire disse ao público para pular ("salta, salta") enquanto mensagens sobre fraternidade universal apareciam nos vídeos no telão. Adolescentes usando top acenavam com bandeiras gigantes vermelhas e azuis do Major Lazer, simbolizando a "paz global" (PARTS, 2016, p. 1).
} 
O caráter de insinuação sobre a amizade parece ser uma das premissas da encenação do espetáculo do Major Lazer em Havana. Estamos diante de um quadro em que os agenciamentos se dão por meio da aproximação com e sob a sombra do passado. "Nós viemos em paz", anuncia Diplo. Trajar camisas que evidenciam a supremacia cubana nos esportes (e o orgulho de Cuba com o beisebol) pelos integrantes do Major Lazer é uma importante forma de encenação de semelhanças. Tal apresentação se reverte em simpatia e adesão. "É impressionante, nós nunca recebemos alguém como ele [Diplo] aqui. Nós amamos música americana", diz uma das meninas, não identificada, entrevistada pela reportagem do site Pitchfork. A fala da menina perpassa possivelmente algumas questões que atravessam um histórico da relação entre estrangeiros e cubanos na ilha.

Estrangeiros, pelo próprio contexto de impossibilidade de saída do país por parte significativa dos cubanos, passaram a ser a forma com que os moradores da ilha tivessem contato com o "mundo externo". Por isso, tornou-se comum o relato de cubanos que "puxam assunto" com turistas, tentam vender charuto, rum, negociar visitas a restaurantes, passeios em carros antigos. Essa relação cria, frequentemente, uma ambiguidade em torno dos vínculos de amizade e negócios entre turistas e moradores. Há um termo, usado pelos próprios cubanos, que é disseminado, embora combatido pela polícia no contexto de Cuba, para definir os indivíduos que se aproveitam da boa-fé de turistas, aplicando possíveis golpes ou permutas de serviços ou produtos por valores financeiros: jinetero. O jinetero pode ser definido como uma espécie de "malandro" cubano, que se dá bem, é perspicaz, audaz e quer tirar vantagem sobre o interlocutor. Trata-se de uma forma ofensiva de classificar alguém, no entanto, há áreas mapeadas pelos moradores de grandes cidades como Havana, em que a prática de jineteros ocorre livremente: o Malecón, onde acontece o show do Major Lazer, por exemplo, é uma região em que jineteros costumam circular.

A prática dos jineteros parece ser uma espécie de conduta cultural que desliza sobre as relações entre estrangeiros e cubanos. É importante sublinhar que jineteros podem ser homens ou mulheres e que, frequentemente, as relações entre estrangeiros e jineteros se baseiam em interesses sexuais, prostituição ou mediação de serviços sexuais. Por isso, é preciso colocar em ênfase que a relação de parte da juventude cubana com os artistas do Major Lazer também estaria sob a fantasmagoria de uma erotização em torno da figura do estrangeiro, dos jogos de poder e sensualidade que regem homens e mulheres em suas teias de produção de sentidos e sensibilidades atreladas a interesses sexuais. "Onde estão meus cubanos?", grita DJ Walshy Fire, atestando para si uma espécie de pertencimento à multidão que assiste à apresentação. Enquanto falam e acenam bandeiras com escritos "global peace" (paz global), os integrantes do Major Lazer conduzem a multidão, negociando batidas eletrônicas em escalas mais ou menos aceleradas.

\section{Fincar a bandeira de Cuba em Cuba - por um estrangeiro}

É inevitável considerar que a relação entre duas nações que viveram sob tensão política e diplomática traga também aportes de metáforas ligadas a conquistas territoriais, 
disposições bélicas e acionamentos militaristas. Nesse sentido, os rituais ligados às conquistas territoriais podem funcionar como importante potência mnemônica nas negociações imagéticas de um espetáculo. Cabe aqui pensar como um show de música também se configura num importante lugar de reivindicação identitária, com fãs e frequentadores ostentando suas origens por meio de bandeiras, faixas ou roupas com referências a seus países. Num show de música pop como aparente espaço de encontros e tensões de nacionalidades, espécie de ambiente em que, de maneira usual, é possível falar da glorificação de imaginários ligados à anglofilia - dos Estados Unidos e da Inglaterra -, a reivindicação de origem por meio de bandeiras de fãs parece ser um dos epicentros para se pensar deslocamentos, nomadismos, peregrinações e conquistas de espacialidades por grupos que não pertencem àquele contexto. Aqui é preciso acionar Regev (2013) na medida em que, para o autor, a exacerbação de texturas nacionais em shows de música pop parece ser o reconhecimento de uma alteridade, de algo que precisa ser exposto, dito, conquistado. É comum que fãs de música pop que não moram em países como Estados Unidos e Canadá, nem na Europa, se desloquem, por exemplo, de nações da América Latina para assistirem a concertos nos Estados Unidos ou na Inglaterra ${ }^{7}$. Esse deslocamento, que pode também ser chamado de peregrinação, indica a performatividade da conquista territorial como metáfora do sacrifício para se estar ali, da evidência de um gostar de um artista que se reverte em deslocamento e presença.

No caso de Cuba, a premissa se inverte: uma vez que, diante de todas as medidas restritivas para que os cidadãos cubanos emigrem, soa impensável que moradores da ilha consigam peregrinar para assistir a algum espetáculo de música pop no exterior. É por isso que podemos falar de uma espécie de contexto cubano de acionamento do pertencimento à Nação-Cuba por parte dos artistas que ali se apresentam. Ostentar bandeiras, roupas de atletas, falar "em nome de Cuba" é um tipo de performance frequentemente incorporada nos concertos. A bandeira de Cuba também funciona como importante aparato de norteamento das ações que se desenrolam no palco.

Se tomarmos o ato de fincar a bandeira de um país no território conquistado como uma metáfora de domínio e poder, podemos fazer leituras sobre a encenação desse ato no espetáculo. Queremos apontar a contradição do ato realizado neste contexto. No momento em que entoa o maior hit do grupo, Lean On, o DJ Diplo se dirige para o destacado do palco e ergue a bandeira de Cuba. Ele fica estático, segurando a bandeira enquanto as batidas eletrônicas regem a dança da plateia que assiste ao show. Não se trata de um gesto rápido e efêmero. Ao contrário, é um gesto marcado pela determinação de um momento: ele, Diplo; ela, a bandeira de Cuba (Fig. 3). Em certa medida, o gesto de erguer a mão com a bandeira cubana faz com que o próprio corpo de Diplo se reverta em parte

7 Turnês são séries consecutivas de shows, que envolvem gastos com produção e execução de artefatos de palco, englobando um número de concertos relativamente pequeno dentro de uma temática, e que se tornam objeto de desejo de fãs de música pop. "Para o fã, é a oportunidade de ver seu artista favorito, especialmente se vive em uma região que não está frequentemente inclusa no circuito das tours" (CONNOLLY e KRUEGER, 2005, p. 12). 
da bandeira - o mastro -, evidenciando uma lógica de pertencimento ao objeto encenado. $\mathrm{O}$ artista encena uma maneira de se fincar ao território cubano a partir do gesto.

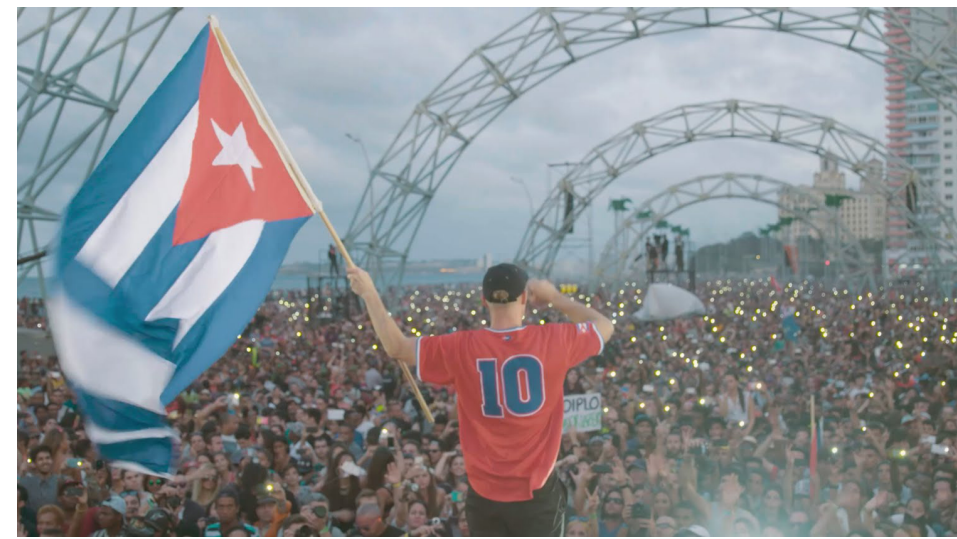

Fig. 3. Diplo segura a bandeira de Cuba

Neste caso, embora o artista apareça segurando a bandeira de Cuba, não deixa de ser emblemático que se destaque o contexto em que se dá a ação. A Tribuna Anti-imperialista está disposta em frente à embaixada dos Estados Unidos em Havana, onde existem mastros para hasteamento de bandeiras que, nesta ocasião, estão vazios. A imagem de Diplo erguendo, estático, a bandeira de Cuba, no palco da Tribuna Anti-imperialista, ganha, como figura de fundo, mastros vazios em que - em tese - se hasteariam bandeiras norte-americanas e também de países que poderiam estar em visita àquela embaixada. Se tomarmos que o prédio da embaixada dos Estados Unidos é, em si, uma marca territorial norte-americana em Cuba, a imagem de Diplo cravando a bandeira de Cuba em solo cubano desenha uma certa atribuição de: 1) tentativa de pertencimento desse sujeito que se ergue como mastro imaginário na bandeira cubana na ocasião do concerto em solo pertencente ao inimigo político; 2) função do estrangeiro, por sua presença naquele contexto, como o que reforça a ideia de pertencimento do cubano à sua terra, evocando preceitos ligados a uma relação de encantamento e ambiguidade; 3) reconhecimento, por parte do norte-americano, da história e da resistência de Cuba no contexto caribenho e mundial, diante de um histórico de embargo econômico e de tensões e discordâncias políticas entre os dois países (EUA e Cuba). Esse mapeamento das controvérsias dos atos performáticos parece reforçar a importância de um debate que não se faça binário, na medida em que se refuta a ideia de que estamos diante de atos imperialistas ou ancorados nas relações unilaterais de poder. A tentativa é perceber que poder e resistência, imposição e sugestão, são também artefatos cênicos que engendram formas de olhar, lembrar, agir e, portanto, viver politicamente relações diplomáticas entre nações. 


\section{Considerações finais}

A partir do concerto do grupo Major Lazer, realizado em Havana, em 2016, dias antes da chegada do presidente Barack Obama a Cuba, postula-se que disposições performáticas ligadas à música pop são formas de encenação de políticas culturais para habitantes da ilha socialista capazes de evidenciar as contradições de um histórico de tensões geopolíticas entre Estados Unidos e Cuba. A Tribuna Anti-imperialista, um local em que se proferiam discursos contra os Estados Unidos, foi palco de um espetáculo em que 90\% das canções eram em língua inglesa e em que era possível ver jovens cubanos usando roupas e artefatos de moda, com imagens e dizeres da bandeira dos Estados Unidos, e produtos culturais ligados à cultura pop anglófila. No entanto, ao contrário de postularmos a premissa de que estaríamos visualizando um certo triunfo imperialista em terras cubanas, sustentamos que se trata de um processo inacabado de construção de sentidos dos viventes da ilha de Cuba diante das contingências existenciais cotidianas: os cerceamentos em função do embargo econômico dos Estados Unidos, as limitações em torno do acesso a bens de consumo resultantes de políticas restritivas do governo cubano, as formas de acesso a produtos da cultura pop por vias alheias às normas estatais, acionando saberes que tangenciam os fluxos midiáticos e a ressignificação que os produtos musicais assumem quando experienciados no contexto cubano.

Enquanto o Major Lazer encaminha-se para terminar a apresentação, vejo meu amigo punk, Leandro, tirando fotos com os amigos. Muitas poses, selfies, retratos em grupos. Todos estão animadíssimos, já altos, bebendo rum e dançando a tal música eletrônica de que, insistem em afirmar, não gostam. Naquele momento, olho para meu celular e me dou conta de que estou sem internet e de que, diante do acesso limitado de internet em Cuba, poderíamos imaginar que as pessoas não passassem o show inteiro entre fotografar os artistas, tirar selfies e gravar vídeo. Percebo: passei o show inteiro sem comentar aquele espetáculo em alguma rede social - se estivesse no Brasil, por exemplo, dificilmente eu teria uma experiência offline como aquela em Cuba. Leandro diz para o amigo que, quando der, posta a foto dos dois no Facebook.

Thiago Soares é professor do Programa de Pós-Graduação em Comunicação da UFPE.

thikos@gmail.com

\section{Referências}

ADORNO, T. Sobre música popular. In: COHN, Gabriel (org.). Theodor Adorno: Sociologia. 2. São Paulo: Ática, 1994. 
AGAMBEN, G. O que é o contemporâneo? e outros ensaios. Chapecó: Argos, 2013.

AUSTIN, J. L. How to do things with words. $2^{\text {a }}$ ed. Cambridge: Harvard University Press, 1975.

BAKHTIN, M. Marxismo e filosofia da linguagem. São Paulo: Hucitec, 1988.

BARTHES, R. Mitologias. São Paulo: Difel, 2003.

CONNOLLY, M.; KRUEGER, A. B. Rockonomics: the economics of popular music. Cambridge: National Bureau of Economic Research, 2005.

COOPER, B. L. A popular music perspective: challenging sexism in the social studies classroom. In: The Social Studies, n.71, p. 1-8, 1981.

COSCARELLI, J. Diplo and Major Lazer bring their brand of music to Cuba. The New York Times. New York, 2016. Disponível em: <http://www.nytimes.com/2016/03/08/arts/music/diplo-and-majorlazer-bring-their-brand-of-music-to-cuba.html?_r=1 >. Acesso em 13 Mar. 2016.

DÁMASO, F. Una avenida com muchos nombres. Diario de Cuba. Havana, 2014. Disponível em: <http://www.diariodecuba.com/cuba/1406364657_9679.html>. Acesso em 13 Mar. 2016.

DERRIDA, J. Politcs of friendship. New York: Verso, 1997.

FRITH, S. Music for pleasure: essays in the sociology of pop. Cambridge: Polity, 1988.

HARKER, D. One for the money: politics and popular song. London: Hutchinson, 1980.

HERNANDEZ, M. Major Lazer em el Paraíso de la Electronica. Disponível em: <http://www.granma. cu/cultura/2016-03-07/major-lazer-en-el-paraiso-de-la-electronica-fotos-07-03-2016-00-03-29>. Acesso em $1^{\circ} \mathrm{Abr} .2016$.

HOGGART, R. The uses of literacy. Harmondsworth: Penguin, 1957.

PARTS, S. What Cuba thought of Major Lazer's historic Havana show. Pitchfork. Chicago, 2016. Disponível em: <http://pitchfork.com/thepitch/1047-what-cuba-thought-of-major-lazers-historichavana-show/>. Acesso em 13 Mar. 2016.

REGEV, M. Pop-rock music: aesthetic cosmopolitanism in late modernity. London: Polity, 2013.

ROACH, J. Cities of the dead: Circum-Atlantic performance. New York: Columbia University Press, 1996.

TAYLOR, D. O arquivo e o repertório: performance e memória cultural nas Américas. Belo Horizonte: Editora da UFMG, 2013.

THORNTON, S. Club cultures: music, media and subcultural capital. London: Polity, 1995.

WEINSTEIN, D. The sociology of rock: an indisciplined discipline. In: Theory, culture and society, n. 8, p. 97-109, 1991.

Artigo recebido em abril e aprovado em julho de 2016. 